Article

\title{
What Does Vietnam Gain When Its Currency Depreciates?
}

\author{
Nguyen Thi Thanh Binh $\mathbb{1}$
}

check for

updates

Citation: Thi Thanh Binh, Nguyen. 2021. What Does Vietnam Gain When Its Currency Depreciates? Economies 9: 185. https://doi.org/10.3390/ economies 9040185

Academic Editors: Robert Czudaj and Andreia Dionísio

Received: 12 October 2021

Accepted: 18 November 2021

Published: 19 November 2021

Publisher's Note: MDPI stays neutral with regard to jurisdictional claims in published maps and institutional affiliations.

Copyright: (C) 2021 by the author. Licensee MDPI, Basel, Switzerland. This article is an open access article distributed under the terms and conditions of the Creative Commons Attribution (CC BY) license (https:/ / creativecommons.org/licenses/by/ $4.0 /)$.
Department of Accounting, Chaoyang University of Technology, Taichung City 41349, Taiwan; tbnguyen@cyut.edu.tw

Abstract: The study investigates how the depreciation of the Vietnam dong (VND) against the US dollar (USD) affected export turnover and the stock market in Vietnam during the period from 2000 to 2020. A Markov triple regime-switching model is developed for time-series data involving multistructural breaks. Empirical results reveal that the impact of exchange rates on export turnover and stock price existed both in the long and short run. In the short run, the depreciation of VND led to (i) an increase in export turnover after 12 months; (ii) a decrease in export turnover of the high-growing regime in the short term; (iii) a reduction in stock returns in most cases. In addition, the common cycle from order receipt, preparation, production, and export is about 12 months for all states. The high volatility of export turnover was associated with high export growth. The commonly used phrase of "high risk, high return" seems to not be true for Vietnam's stock market. The results of this study suggest the feasibility of a slight appreciation of VND against USD, which is the key to escape from being labeled a currency manipulator by the US Treasury.

Keywords: currency; export; stock returns; triple regime-switching model; Vietnam

JEL Classification: C22; L85; P44

\section{Introduction}

Exchange rates are a hot topic for academic debate and speculative market forces. There are two macroeconomic variables of emerging economies such as Vietnam that play an important role with foreign investors, namely, inflation and exchange rate. The literature de facto has not yet paid much attention to studying the advantages and disadvantages of currency devaluation, and its connection to exports and the stock market, which has seen different changes in the implementation of the monetary policy and exchange rates over the past two decades. In particular, the US Department of the Treasury officially labeled Vietnam a currency manipulator at the end of 2020. Being labeled a currency manipulator puts Vietnam at risk of being restricted by the US under US law from accessing procurement contracts, and government and development financing, under US law.

A depreciating currency theoretically supports exports. A weak currency means that domestic goods are cheaper abroad. Therefore, it increases both exports and stock prices, as more businesses raise their capital through the securities market, pushing up the stock price. There is a growing economic literature dealing with the possible effects of exchange rates on exports, such as Sercu and Hulle (1992); Arslan and Wijnbergen (1993); Aristotelous (2001); Hall et al. (2010); Berman et al. (2012); Choudhri and Hakura (2015); Paudel and Burke (2015); Nguyen and Do (2020); Chen et al. (2021). However, there is no clear consensus in the empirical literature on the direction of the relationship, and positive, negative, mixed, or no effects. One of the first studies investigating the interaction between exchange rates and stock prices was conducted by Franck and Young (1972). Numerous articles then successively reported the short- and long-run relationship between them, such as Fang and Loo (1996); Ajayi et al. (1998); Kanas (2000); Homma and Benzion (2005); Phylaktis and Ravazzolo (2005); Hau and Rey (2006); Pan et al. (2007); Caporale et al. (2014); BahmaniOskooee and Saha (2015); Reboredo et al. (2016); Sui and Sun (2016); Dahir et al. (2018); 
Andriansyah and Messinis (2019); Lee and Brahmasrene (2019); Nguyen et al. (2020); Ding (2021). However, the results and direction of the relationship between exchange rate and stock price are contradictory across studies.

The triple regime-switching model was developed for examining whether the depreciation of the Vietnam dong (VND) to the US dollar (USD) could lead to an increase in future export turnover and stock price in Vietnam. Over the period from 31 July 2000 to 31 December 2020, empirical results show that the depreciation of VND most effectively promotes export growth in a moderate-growth state to which the group of agricultural products, raw materials, and unprocessed goods belong. The high-growth state where the depreciation of VND negatively affects exports should belong to the FDI sector, where export prices do not depend much on the exchange rate in the short term. Meanwhile, the effect on the stock market is generally negative. Empirical results contradict the usual wisdom of "high risk, high return" in the stock market of Vietnam.

This study makes three important contributions to the existing literature. First, as far as it could be ascertained, this is the first study investigating the gain and loss of VND depreciation on export turnover and stock price in Vietnam within asymmetric frameworks. Second, this is one of few studies that take the triple regime model into account for more appropriate results. Third, empirical results suggest that the effect of exchange rates on export and stock price exists both in the long and short run.

These results contribute to the discussion of Vietnam's monetary policy when the US raised the issue of currency manipulation and put Vietnam on the observation list. The remainder of this paper is organized as follows. Section 2 presents a data description. Section 3 outlines the empirical methodology and analysis of the results. Section 4 offers conclusions.

\section{Data and Descriptive Statistics}

\subsection{Data}

Data for this study were obtained from two sources. Monthly data of the export value (EXP) and VND/USD exchange rates (EXR) of Vietnam were obtained from the database of the International Monetary Fund (IMF) from 31 July 2000 to 31 December 2020. The monthly data of VN-INDEX (VNI) were taken from Vietstock in the same period.

\subsection{Descriptive Statistics}

Let EXR, EXP, and VNI denote the vector of exchange rates (EXR), export value (EXP), and VN-INDEX (VNI), respectively. The trends of EXR, EXP, and VNI during the period of 31 July 2000 to 31 December 2020 are plotted in Figure 1. EXP was on an upward trend during the sample period. A significant decrease occurred every February. The VNI was rather stable within the range from 101 to 500 points in the first 5 years since trading commenced on 28 July 2000. In the period from June 2006 to June 2008, Vietnam's index had an unexpectedly strong growth and nearly peaked at 1138 points in March 2007. The 2008 global economic crisis caused the downturn of Vietnam's stock index, which suddenly fell sharply below 300 points in early 2009. Although it was so badly affected by the crisis, VNI quickly recovered after the bleak period, as evidenced by the second half of 2009 to the end of 2020. Vietnam's index maintained continuity and increased, while the exchange rates of VND to USD remained stable except for the drastic increase in the period of April 2008 to February 2011. Table 1 reports the descriptive statistics of EXP, EXR, and VNI, showing that Vietnam's HOSE index reached its maximum at 1174 points in March 2018, export value at USD 27,702.47 million in August 2020, and an exchange rate at VND23,261/USD in May 2020. In addition, skewness and kurtosis show the right-skewed and leptokurtosis of stock return distribution. Jarque-Bera statistics significantly reject the normality of three variables. 

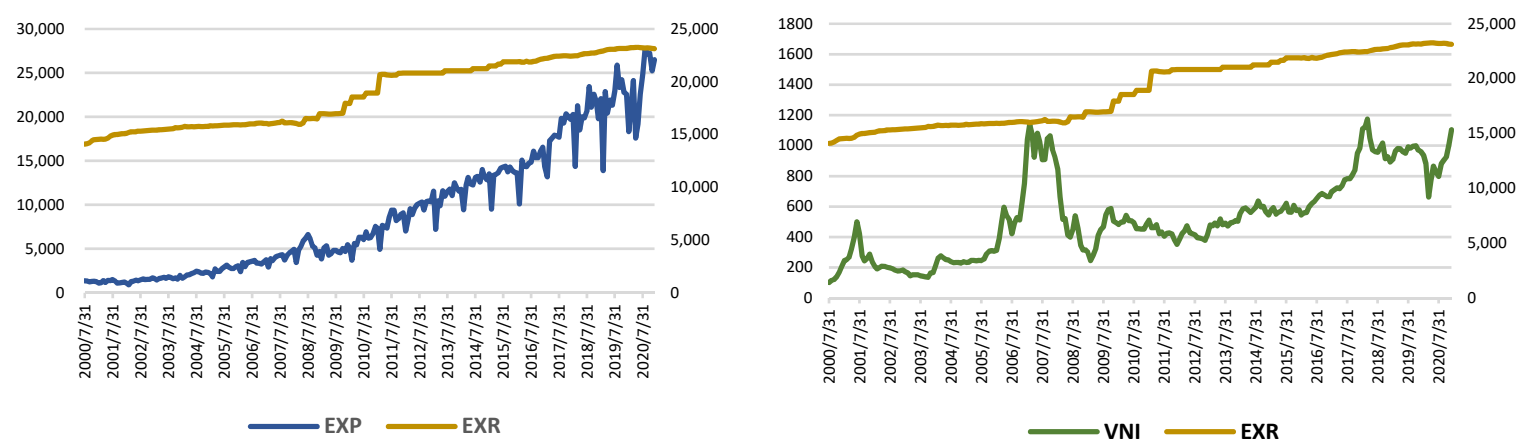

Figure 1. Trend of exchange rate (EXR), export (EXP) and stock index (VNI).

Table 1. Descriptive statistics.

\begin{tabular}{cccc}
\hline Statistics & EXP & EXR & VNI \\
\hline Mean & 9082.02 & $18,880.34$ & 533.49 \\
\hline Standard deviation & 7287.28 & 3069.58 & 273.02 \\
\hline Skewness & 0.76 & 0.02 & 0.49 \\
\hline Kurtosis & 2.43 & 1.32 & 2.27 \\
\hline J-B & $26.73^{* * *}$ & $28.82^{* * *}$ & $15.21^{* * *}$ \\
\hline$L B(12)$ & $2402.1^{* * *}$ & $2669.2^{* * *}$ & $1908.9^{* * *}$ \\
\hline$L B^{2}(12)$ & $1408.9^{* * *}$ & $2253.6^{* * *}$ & $913.61^{* * *}$
\end{tabular}

Note: Sample period spans from July to December 2020. J-B, statistic of Jarque-Bera normal distribution test. Ljung-Box test used for testing for variable autocorrelation. $L B(12)$ that uses the lag length of 12 months is the statistics of the Ljung-Box test. $L B^{2}(12)$ that applies the lag length of 12 months is the Ljung-Box statistics for squared residuals. ${ }^{* * *}$ indicates $1 \%$ significance level.

Figure 2 shows that, beginning in 2007, the central bank began to loosen the range of effective rates from $0.25 \%$ to $0.5 \%$; at the end of 2007 , it was further enlarged to 0.75 . During this period, the exchange rate regime remained with a small oscillation amplitude. The year 2008 was eventful with many unexpected occurrences for the exchange rate of VND/USD. In the first half of 2008, the central banks applied tightening monetary measures; the interest base rate was adjusted from $8.25 \%$ to $8.75 \%$, and inflation was pushed. In the second half of 2008, the rate of VND/USD suddenly increased from 16,600 to 16,998. Then, 2009 was when monetary policy had to face unpredictable challenges arising from the inadequacies of the economy, and the adverse impact of the financial crisis and economic recession. To increase supply and stabilize the foreign exchange market, banks deployed more drastic measures, such as widened exchange rates from $+/-3 \%$ to $+/-5 \%$. Generally, the gap between the average monthly return of stock $(0.97 \%)$ and the growth of VND/USD $(0.20 \%)$ was narrow $(0.70 \%)$. Since the outbreak of the COVID-19 pandemic at the end of January 2020, the US Federal Reserve (FED) has lowered its operating interest rates to $0-0.25 \%$ (lower-upper range) and relaunched the quantitative easing $(\mathrm{QE})$ in an effort to rescue the US economy from the pandemic-induced recession. The unprecedented easing policy along with the negative economic growth outlook of the US in 2020 caused the dollar to decline. On 2 November, the dollar strength index fell 2.4\% since the beginning of the year. However, as of 30 October, the VND/USD exchange rate has increased slightly by $0.2 \%$ compared to the beginning of the year. If investors sell the US dollar (USD) for the Vietnamese dong (VND) to invest in the stock market, their returns adjusted for inflation were negative from July to December 2020, and the gap between the average growth rate of EXP and EXR was about 1\%. 

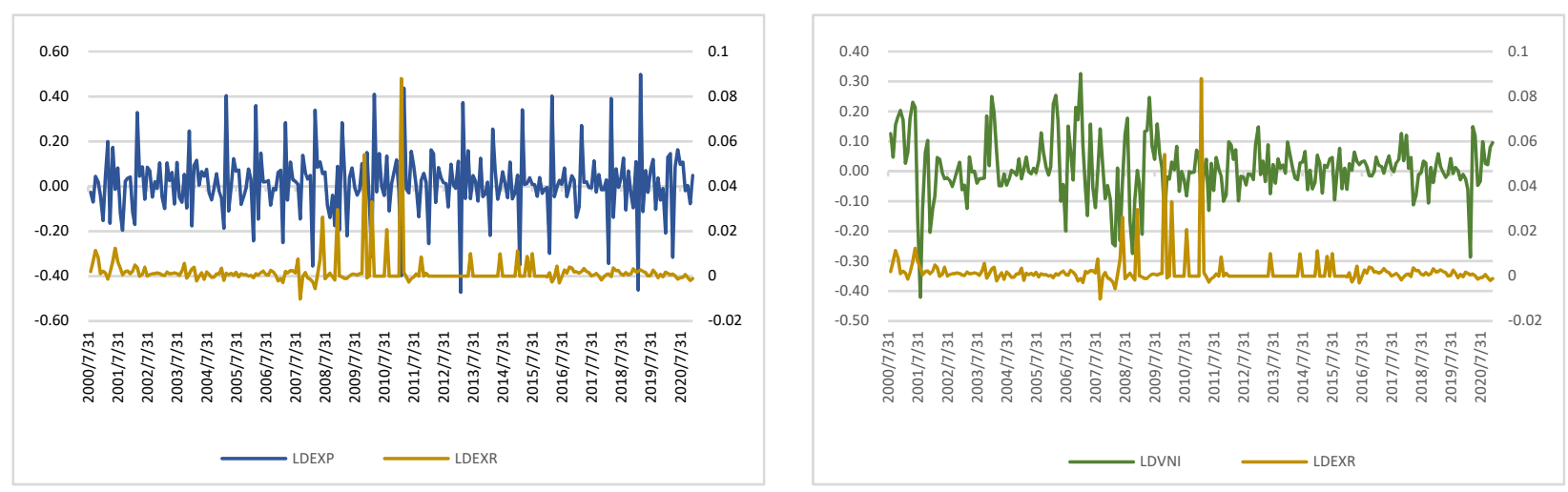

Figure 2. Trend of exchange rate volatility, export growth, and stock returns.

\section{Empirical Method and Results}

\subsection{Empirical Method}

The Markov switching dynamic regression (MSDR) of Hamilton (1989), namely, the regime-switching model, is one of the most popular nonlinear time-series models. It involves multiple structures that can characterize the dynamic behaviors of data under different regimes. The basic model with switching intercept is as follows:

$$
Y_{t}=\mu\left(s_{t}\right)+\beta\left(s_{t}\right) X_{t}+\epsilon_{t}
$$

where

$$
\mu=\left\{\begin{array}{c}
\mu_{1} \text { if } s_{t}=1(\text { Regime } 1) \\
\mu_{2} \text { if } s_{t}=2(\text { Regime } 2) \\
\ldots \\
\mu_{n} \text { if } s_{t}=n(\text { Regime } n)
\end{array}\right.
$$

$Y_{t}$ is a dependent variable that follows a process depending on the value of unobserved state $s_{t} . s_{t}$ is assumed to have $\mathrm{n}$ possible regimes. $X_{t}$ is a vector of exogenous variables, $\mu\left(s_{t}\right)$ is the conditional mean of $Y_{t}$ in each specified regime. $\epsilon_{t}$ is an independent and identically distributed (i.i.d.) normal error. The regression model was assumed to be linear in regime $n$.

The Markov switching regression model extends the basic exogenous probability framework by specifying a first-order Markov process for regime probabilities, where $s_{t} \in\{0,1\}$, and regime transitions are calculated according to

$$
\mathrm{P}\left[s_{t}=a \mid s_{t-1}=b\right]=p_{a b}(t)
$$

These probabilities are presented in a transition matrix of an ergodic $n$ regimes Markov process as follows:

$$
p(t)=\left[\begin{array}{ccc}
p_{11}(t) & \ldots & p_{1 n}(t) \\
\ldots & \ldots & \ldots \\
p_{n 1}(t) & \ldots & p_{n n}(t)
\end{array}\right]
$$

where element $a b$ represents the probability of transitioning from regime a in period $t-1$ to regime $\mathrm{b}$ in period $t$.

Following Hamilton's (1989), probabilities can be parameterized in terms of a multinomial logit. As each row of the transition matrix specifies a complete set of conditional probabilities, a separate multinomial specification for each row $a$ of the matrix is as follows:

$$
p_{a b}\left(G_{t-1}, \vartheta_{a}\right)=\frac{\exp \left(G_{t-1}^{\prime} \vartheta_{a b}\right)}{\sum_{s=1}^{n} \exp \left(G_{t-1}^{\prime} \vartheta_{a b}\right)}
$$

where $a=1, \ldots, n, b=1, \ldots, n, \vartheta_{a n}=0$, and $G_{t-1}$ contains a constant. 
The basic switching model can be extended to the Markov switching dynamic regression to allow for dynamics in the form of lagged exogenous variables:

$$
Y_{t}=\mu\left(s_{t}\right)+\sum_{i=1}^{q} \beta_{i}\left(s_{t}\right)\left(X_{t-i}\right)+\sigma\left(s_{t}\right) \epsilon_{t}
$$

where $\epsilon_{t}$ is iid standard normally distributed, and standard deviation $\sigma\left(s_{t}\right)$ is regimedependent.

For testing the relationship between variables, the autoregressive $A R(p)$ process was added to the model for capturing the remained autocorrelation of residuals:

$$
Y_{t}=\mu\left(s_{t}\right)+\sum_{i=1}^{q} \beta_{i}\left(s_{t}\right)\left(X_{t-i}\right)+\sigma\left(s_{t}\right) \epsilon_{t}+\sum_{i=1}^{p} \varphi_{i} Y_{t-i}
$$

\subsection{Empirical Results}

Let $Y_{t}$ denote the vector of EXP, EXR, and VNI. Then, $Y_{t}$ yields the annual growth rates after taking the differences of its logs:

$$
g_{t}=\log \left(Y_{t}\right)-\log \left(Y_{t-1}\right)
$$

The Markov switching dynamic regression discussed in the preceding section is only suitable for stationary data. The growth rates of EXP, EXR, and VNI are plotted in Figure 2. These three series were stationary after taking the differences in their log. Results of ADF and DF-GLS unit root tests are reported in Table 2. The equations of unit root tests include both a constant and a time trend. The optimal lag length was selected according to the minimal SIC. Testing results showed that three variables were stationary after taking differences in their log.

Table 2. Unit root tests.

\begin{tabular}{lcccc}
\hline \multirow{2}{*}{ Variable } & \multicolumn{2}{c}{ ADF } & \multicolumn{2}{c}{ DF-GLS } \\
\cline { 2 - 5 } & Test Statistic & Lag Length & Test Statistic & Lag Length \\
\hline Level & & & & \\
\hline Ln_EXP & -1.308 & $(12)$ & -1.565 & $(11)$ \\
\hline Ln_EXR & -1.169 & $(0)$ & -2.384 & $(0)$ \\
\hline Ln_VNI & $-3.433^{* *}$ & $(1)$ & & $(1)$ \\
\hline First difference & & & $-2.688^{*}$ & $(12)$ \\
\hline$\Delta$ Ln_EXP & $-6.309^{* * *}$ & $(11)$ & $-15.819^{* * *}$ & $(0)$ \\
\hline$\Delta$ Ln_EXR & $-15.801^{* * *}$ & $(0)$ & $-4.829^{* * *}$ & $(3)$ \\
\hline$\Delta$ Ln_VNI & $-10.853^{* * *}$ & $(0)$ & & \\
\hline
\end{tabular}

Note: Constant and time trend included in all test equations. Maximal lag length applied for the test is 15 periods. Numbers in parentheses are the adequate lag order of the ADF test and DF-GLS test, determined by the minimal SIC. ${ }^{* * * * *}$ and ${ }^{*}$ indicate $1 \%, 5 \%$, and $10 \%$ significance levels, respectively. Critical values of ADF derived from Mackinnon (1996). Critical values of DF-GLS derived from Elliott-Rothenberg-Stock (1996).

The residual-based cointegration test of Engle and Granger (1987) was applied for testing the linear and nonlinear long-run effect of EXR on EXP and VNI. Table 3 summarizes the results of the residual-based cointegration test. Both the Engle-Granger tau statistic (t-statistic) and the normalized autocorrelation coefficient (z-statistic) are uniformly failing to reject the null of no cointegration at conventional levels. These test statistics suggest that it is unable to reject the null hypothesis of no cointegration between variables in both linear and nonlinear models. In other words, the long-term influences of the exchange rate on exports and stock index clearly exist. 
Table 3. Engle-Granger test for cointegration.

\begin{tabular}{ccccc}
\hline \multicolumn{1}{c}{ Direction } & \multicolumn{2}{c}{ Linear Model } & \multicolumn{2}{c}{ Nonlinear Model } \\
\hline & t-Statistic & z-Statistic & t-Statistic & z-Statistic \\
\hline \multirow{2}{*}{ Ln_EXR $\rightarrow$ Ln_EXP } & -1.6251 & -6.059 & -1.503 & -5.201 \\
& $(0.896)$ & $(0.883)$ & $(0.977)$ & $(0.983)$ \\
\hline \multirow{2}{*}{ Ln_EXR $\rightarrow$ Ln_VNI } & -1.945 & -7.876 & -2.082 & -8.763 \\
& $(0.795)$ & $(0.784)$ & $(0.889)$ & $(0.899)$ \\
\hline
\end{tabular}

Note: Long-run influence of Ln_EXR (exchange rate) on Ln_EXP (export) and Ln_VNI (stock index) examined on the basis of residual-based cointegration test of Engle and Granger (1987). Maximal applied lag was 15 periods Optimal lag selected according to SIC. Numbers in parentheses are P values (see MacKinnon (1996) for reference).

The Markov switching dynamic regression shows different dynamics across unobserved regimes using regime-related parameters to adapt to structural breaks or other multistate phenomena. To determine the number of regimes for the MSDR model, the structural break test of Bai-Perron (1998) was applied. This method detects the breakpoints of the relationship between Ln_EXP vs. Ln_EXR and Ln_VNI vs. Ln_EXR. As Table 4 shows, two breakpoints were detected for both equations. In other words, the MSDR model with three states was appropriate for examining the nonlinear dynamic effect of EXR on EXP and VNI. The three states represent low-, moderate-, and high-growth states.

Table 4. Structural breakpoint test.

\begin{tabular}{ccccccc}
\hline & \multicolumn{2}{c}{ Ln_EXP vs. Ln_EXR } & \multicolumn{2}{c}{ Ln_VNI vs. Ln_EXR } \\
\hline Breakpoints & Timepoint & F Value & & Timepoint & F Value & \\
\hline$\leq 1$ & June 2005 & 93.371 & $* * *$ & February 2006 & 73.492 & $* * *$ \\
\hline$\leq 2$ & May 2012 & 68.791 & $* * *$ & January 2013 & 82.922 & $* * *$ \\
\hline$\leq 3$ & & 1.154 & & & 0.000 & \\
\hline
\end{tabular}

Note: Bai-Perron test (1998) applied for detecting breakpoints of the relationship between Ln_EXP vs. Ln_EXR, and Ln_VNI vs. Ln_EXR. F values reject nulls of 0,1 , and 2 breakpoints, but test of 3rd breakpoint did not reject the null. Timepoints of breaks are the first date of the subsequent regime; ${ }^{* * *}, 1 \%$ significance level.

Markov switching dynamic regression was applied to Model 6 using the observations of the whole sample. Estimation results summarized in Tables 5 and 6 were obtained by applying multivariate Markov switching dynamic regression to the after-change sample. $p_{11}$ is the estimated probability of staying in Regime 1 in the next period, and $p_{22}$ is the probability of staying in Regime 2 . The estimated standard deviations for the entire process are represented by $\log (\sigma)$, which shows periods of high and low volatility.

Parameters in Table 5 and smoothing probabilities in Figure 3 characterize the influence of exchange rate on export growth in a given month earlier. Table 5 presents the estimation for five selected periods of exchange rate: same period, 3 months, six months, one year, and two years earlier. As reported in Table 5, $\mu$ denotes the mean of three regimes: Regime 1 is the high growth state of export (mean of $4.3 \%$ ), Regime 2 is the moderate growth state (mean of $0.5 \%$ ), and Regime 3 is the low growth state (mean of $-1.6 \%$ ). The transition probabilities for Regime 1 to 1 and Regime 2 to 2 are $p_{11}$ and $p_{22}$, respectively. Both $p_{11}$ and $p_{22}$ showed that the three regimes were highly persistent. The implied standard deviations of $\log (\sigma)$ are $0.163,0.059$, and 0.003 , respectively, indicating that Regime 1 corresponds to the high-volatility period, Regime 2 corresponds to the medium-volatility period, and Regime 3 corresponds to the low-volatility period. Exchange rate volatility had positive and statistically significant impact on export in all three regimes. 
Table 5. Effect of exchange rate on export growth.

\begin{tabular}{|c|c|c|c|c|c|c|}
\hline \multirow{2}{*}{$\begin{array}{l}\text { Variable } \\
\mu\end{array}$} & \multicolumn{2}{|c|}{$\begin{array}{c}\text { Regime } 1 \\
\text { (High-Growth Period) }\end{array}$} & \multicolumn{2}{|c|}{$\begin{array}{c}\text { Regime } 2 \\
\text { (Moderate-Growth Period) }\end{array}$} & \multicolumn{2}{|c|}{$\begin{array}{c}\text { Regime } 3 \\
\text { (Low-Growth Period) }\end{array}$} \\
\hline & 0.043 & $* * *$ & 0.005 & * & -0.016 & $* * *$ \\
\hline & [0.005] & & [0.003] & & [0.001] & \\
\hline \multirow[t]{2}{*}{$\Delta \mathrm{EXR}_{\mathrm{t}}$} & -2.591 & $*$ & 1.237 & & 0.197 & $* *$ \\
\hline & [1.439] & & [0.791] & & [0.085] & \\
\hline \multirow[t]{2}{*}{$\Delta \mathrm{EXR}_{\mathrm{t}-3}$} & -1.694 & & 2.222 & $* * *$ & -27.745 & $* * *$ \\
\hline & [1.454] & & {$[0.534]$} & & {$[0.441]$} & \\
\hline \multirow{2}{*}{$\Delta \mathrm{EXR}_{\mathrm{t}-6}$} & -3.831 & $* * *$ & 0.616 & & -1.471 & $* * *$ \\
\hline & [0.156] & & [0.466] & & [0.191] & \\
\hline \multirow{2}{*}{$\Delta \mathrm{EXR}_{\mathrm{t}-12}$} & 1.530 & $* * *$ & 1.691 & $* * *$ & 1.922 & $* * * *$ \\
\hline & [0.313] & & [0.422] & & {$[0.126]$} & \\
\hline \multirow[t]{2}{*}{$\Delta \mathrm{EXR}_{\mathrm{t}-24}$} & -3.480 & & 2.211 & $* * *$ & 0.437 & \\
\hline & [1.316] & $* * *$ & [0.124] & & {$[0.340]$} & \\
\hline \multirow[t]{2}{*}{$\log (\sigma)$} & -1.814 & $* * *$ & -2.826 & $* * *$ & -5.872 & $* * *$ \\
\hline & [0.097] & & [0.104] & & [0.265] & \\
\hline $\begin{array}{l}\text { Average } \\
\text { duration }\end{array}$ & 4.426 & & 4.497 & & 1.375 & \\
\hline$\varphi_{1}$ & -0.543 & $* * *$ & & & & \\
\hline$\varphi_{2}$ & -0.200 & $* * *$ & & & & \\
\hline $\mathrm{p}_{11}$ & 2.678 & $* * *$ & & & & \\
\hline $\mathrm{p}_{22}$ & 1.589 & $* * *$ & & & & \\
\hline $\mathrm{Q}_{10}\left(\mathrm{uh}^{-\frac{1}{2}}\right)$ & 1.7996 & (0.987) & & & & \\
\hline$Q_{10}\left(u^{2} h^{-1}\right)$ & 4.646 & (0.914) & & & & \\
\hline $\log L$ & 2144.155 & & & & & \\
\hline $\begin{array}{l}\text { Jote: } \mathrm{Q}_{10}\left(\mathrm{uh}^{-\frac{1}{2}}\right) \\
\text { jung-Box statist } \\
\text { naximum likelih } \\
\text { tatistics. }{ }^{*}, * * \text { and }\end{array}$ & $\begin{array}{l}\text { and } Q_{10}\left(u^{2} l\right. \\
\text { ic, respective } \\
\text { od function. } \\
* * * \text { represent }\end{array}$ & $\begin{array}{l}\text { represent } \\
11 \text { and } \mathrm{p}_{22} \\
\text { les inside sq } \\
5 \% \text { and } 1\end{array}$ & $\begin{array}{l}\text { th standardiz } \\
\text { and for Mark } \\
\text { are brackes ar } \\
\text { significant lev }\end{array}$ & $\begin{array}{l}\text { liond sq } \\
\text { ion prob } \\
\text { errors. } \\
\text { tively. }\end{array}$ & $\begin{array}{l}\text { ced standard } \\
\text { lities. Log } \mathrm{L} \\
\text { ues inside p }\end{array}$ & $\begin{array}{l}\text { sidual o } \\
\text { value o }\end{array}$ \\
\hline
\end{tabular}

Results show that the significant signs of coefficients on the lagged exchange rate were not consistent in the three regimes. The depreciation of VND against the USD one year earlier positively affected export growth in all three regimes. These positive effects existed in all cases of Regime 2, where the influence of VND depreciation in three months and two years earlier on export growth was positive and significant. Regime 2 might be the group of agricultural products, raw materials, and unprocessed goods. The depreciation of VND most effectively promotes export growth in a moderate growth state and in one year earlier for all regimes. However, it has the opposite effect in most of the remaining cases of Regimes 1 and 3. Regime 1 where the devaluation of VND negatively affects export should belong to the FDI sector as their export prices do not depend much on the devaluation of VND in the short term. This sector greatly contributed in increasing Vietnam's export capacity and accounts for over $70 \%$ of the total export turnover of the country.

Table 6 shows that Regime 1 belongs to the low-return state and has a mean of $-2.30 \%$; Regime 2 is the moderate-return state that has a mean of $0.04 \%$; Regime 3 is the high-return state that has a mean of $1.50 \%$. The estimates of $p_{11}$ and $p_{22}$ imply that the three regimes are highly significant.

Results indicate that the depreciation of VND against the USD three months earlier positively and significantly affected stock returns in Regime 2, but it did not in Regimes 1 and 3 . Results also indicate that the depreciation of VND negatively and significantly affected stock returns in Regime 3 when stock returns were high. 
Table 6. Effect of exchange rate growth on stock returns.

\begin{tabular}{|c|c|c|c|c|c|c|}
\hline \multirow{2}{*}{$\begin{aligned} \text { Variable } \\
\mu\end{aligned}$} & \multicolumn{2}{|c|}{$\begin{array}{c}\text { Regime } 1 \\
\text { (Low-Return Period) }\end{array}$} & \multicolumn{2}{|c|}{$\begin{array}{c}\text { Regime } 2 \\
\text { (Medium-Return Period) }\end{array}$} & \multicolumn{2}{|c|}{$\begin{array}{c}\text { Regime } 3 \\
\text { (High-Return Period) }\end{array}$} \\
\hline & -0.023 & & 0.004 & & 0.015 & \\
\hline & [0.032] & & [0.006] & & [0.009] & \\
\hline \multirow[t]{2}{*}{$\Delta \mathrm{EXR}_{\mathrm{t}}$} & -2.265 & & 1.912 & & -1.693 & $* * *$ \\
\hline & [3.919] & & [1.528] & & {$[0.606]$} & \\
\hline \multirow[t]{2}{*}{$\Delta \mathrm{EXR}_{\mathrm{t}-3}$} & 4.673 & & 4.019 & $* * *$ & -1.030 & * \\
\hline & [3.966] & & [1.303] & & {$[0.615]$} & \\
\hline \multirow[t]{2}{*}{$\Delta \mathrm{EXR}_{\mathrm{t}-6}$} & 5.748 & & -3.934 & $* * *$ & 0.291 & \\
\hline & [5.645] & & [0.796] & & [0.699] & \\
\hline \multirow[t]{2}{*}{$\Delta \mathrm{EXR}_{\mathrm{t}-12}$} & 16.615 & * & -1.532 & $* *$ & 0.623 & \\
\hline & [9.142] & & [7.649] & & [0.651] & \\
\hline \multirow[t]{2}{*}{$\Delta \mathrm{EXR}_{\mathrm{t}-24}$} & 24.206 & * & -0.324 & & -0.656 & \\
\hline & [13.596] & & [0.676] & & [0.605] & \\
\hline \multirow[t]{2}{*}{$\log (\sigma)$} & -1.994 & $* * *$ & -3.780 & $* * *$ & -2.817 & $* * *$ \\
\hline & [0.110] & & [0.123] & & [0.094] & \\
\hline $\begin{array}{l}\text { Average } \\
\text { duration }\end{array}$ & 16.244 & & 4.879 & & 6.500 & \\
\hline$\varphi_{1}$ & 0.192 & $* * *$ & & & & \\
\hline$\varphi_{2}$ & 0.057 & & & & & \\
\hline $\mathrm{p}_{11}$ & 2.724 & $* * *$ & & & & \\
\hline $\mathrm{p}_{22}$ & 1.588 & $* *$ & & & & \\
\hline $\mathrm{Q}_{10}\left(\mathrm{uh}^{-\frac{1}{2}}\right)$ & 3.535 & $(0.896)$ & & & & \\
\hline $\mathrm{Q}_{10}\left(\mathrm{u}^{2} \mathrm{~h}^{-1}\right)$ & 5.988 & $(0.816)$ & & & & \\
\hline $\log L$ & 289.299 & & & & & \\
\hline
\end{tabular}

Results show estimates of $\log (\sigma)$ in the high-, low-, and medium-volatility regimes. Implied standard deviations were $0.136,0.023$, and 0.059 , respectively. The commonly used phrase in investment of "high risk, high return" does not hold in the case of Vietnam's stock market, as taking a high risk does not guarantee that relative high returns can be achieved. Regime 1, with high risk and low returns, lasted the longest. The Ljung-Box diagnostic test statistics $Q_{10}\left(u h^{-\frac{1}{2}}\right)$ for the residuals and $Q_{10}\left(u^{2} h^{-1}\right)$ for the squared residuals indicate that models in Tables 5 and 6 can describe salient features in export growth rates and stock returns.

Figure 3 is the plot of the smoothing probabilities $\mathrm{P}\left(s_{t}=a \mid \aleph_{T}\right)$ of the triple regime model that explores how exchange rate growth affects export growth and stock returns. The plot of exchange rate effect on export growth ( $\Delta$ Ln_EXR $\rightarrow \Delta$ Ln_EXP) shows that both the red vertical dashed lines at June 2005 and May 2012 are in Regime 2. The highest volatility period was 2008-2009, which coincided with the global financial crisis. This high volatility carries high export growth caused by the depreciation of VND one year earlier.

The plot of exchange rate effect on stock returns $\left(\Delta \mathrm{L} n \_E X R \rightarrow \Delta \mathrm{Ln} \_\mathrm{VNI}\right)$ shows that most of the high variance regime is located in the first half of the sample. The probabilities of one appeared the most in Regime 1 during February 2006 to May 2009, where the red vertical dashed lines signify the first breakpoint identified by the Bai-Perron test (1998) 
of the stock index in February 2006. That is, the stock is in a state of low return and high volatility. The second breakpoint occurred at January 2013 where Regime 2 is switched to Regime 3, and the stock is in a state of high return.
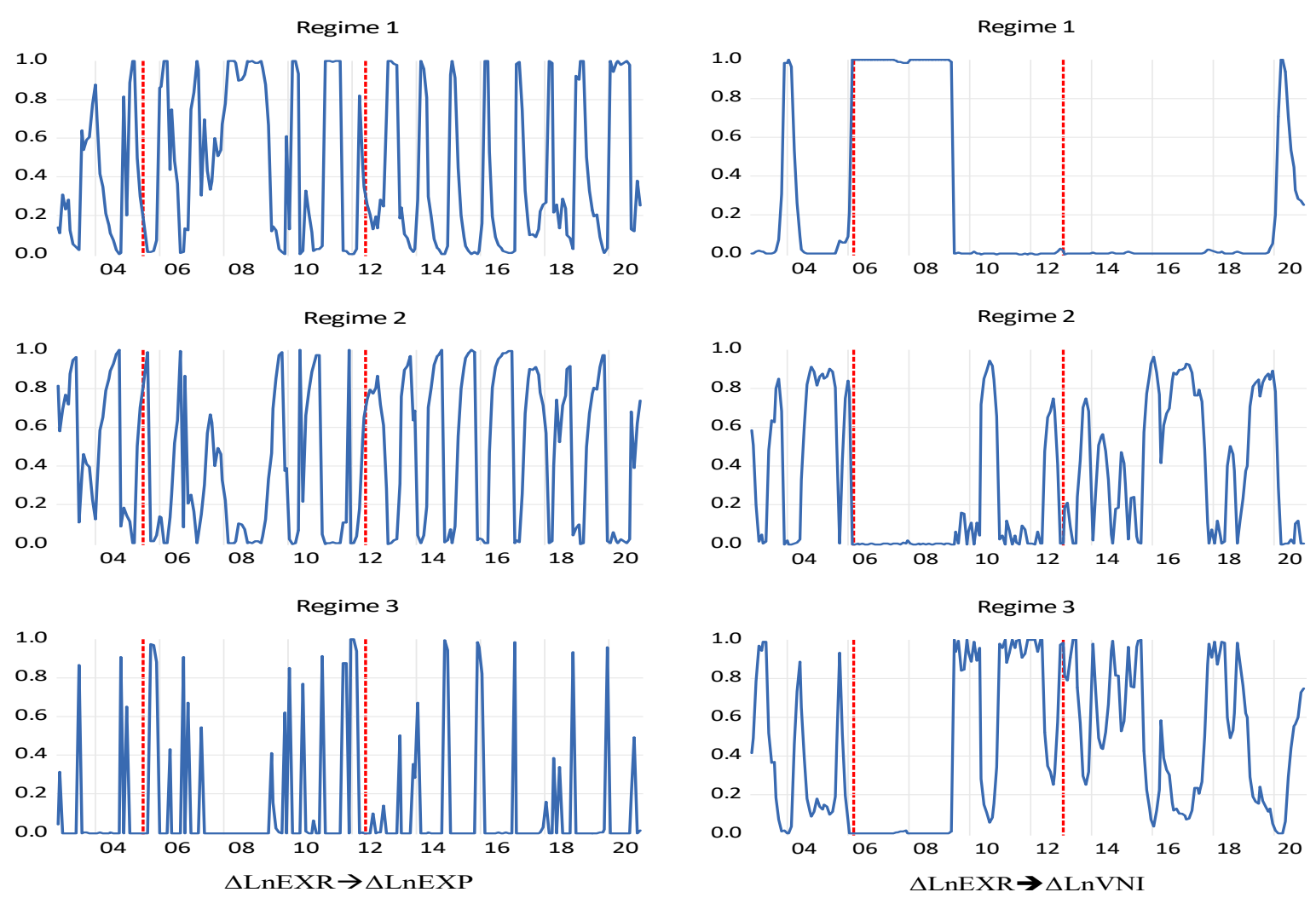

Figure 3. Markov switching smoothed probabilities of triple regime model.

Figure 4 plots the impact of the risk generated by the exchange rates on the export and stock market. It shows that the shock of exchange rates on export is negative, then becomes positive, and slowly diminishes. This implies that the exchange rate first makes the export decrease then slowly rise with a small magnitude, and disappears after 12 months. From the impact on the stock market, it can be found that the effect is not significant and then slowly disappears after 6 months.

To summarize, this study examined the behaviors of exports and stock prices to changes in exchange rates in Vietnam. The VND/USD exchange rate is carefully monitored and controlled by the State Bank of Vietnam (SBV). Generally, the SBV manages the exchange rates to vary within a given range. When exchange rates rise sharply in response to political or economic shocks, the SBV usually intervenes in the market to ensure the stability of the exchange rates. As such, Vietnam's export and stock market may behave differently during different regimes.

The long-term effect of exchanges rates' volatility on the export and stock markets do exist in Vietnam. The signs of these effects are examined with the triple regime-switching model. VND devaluation only significantly increases the export value after 12 months. This shows that the cycle from order receipt, preparation, production, and export is usually 12 months. It also works for most of the periods during the regime of moderate export growth, and it has the opposite effect on the regime of high growth. When considering the combined effect of all 3 regimes, the VND depreciated causes the export value to decrease in the first 2 months; then, it gradually increases but with a narrow range and disappears after 12 months. This implies that, when export products are priced in USD, their prices are lower, causing the export turnover to be lower in the first 2 months, then gradually increasing in the following months on the basis of the devaluation of VND. The devaluation 
of VND increases stock returns only effectively in the previous 3 months, and this effect only significantly appears in the medium-return period and does not last long. In most remaining cases, the opposite is true. Its combined effect is not significant. Empirical results contradict the usual wisdom of "high risk, high return".

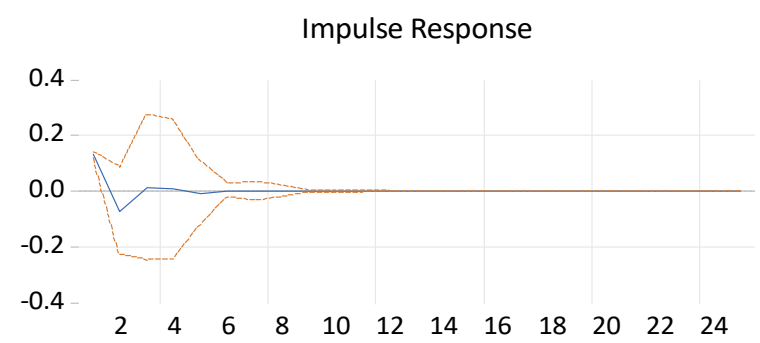

Accumulated Response

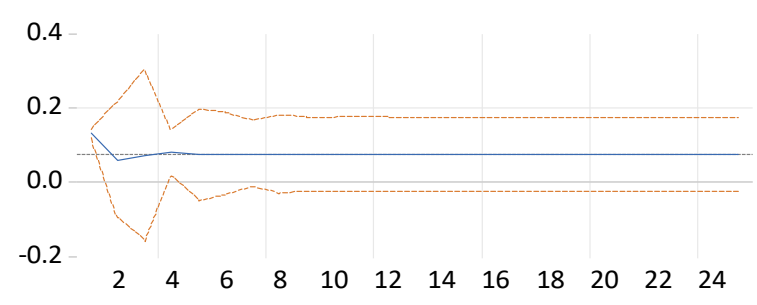

Impulse Response
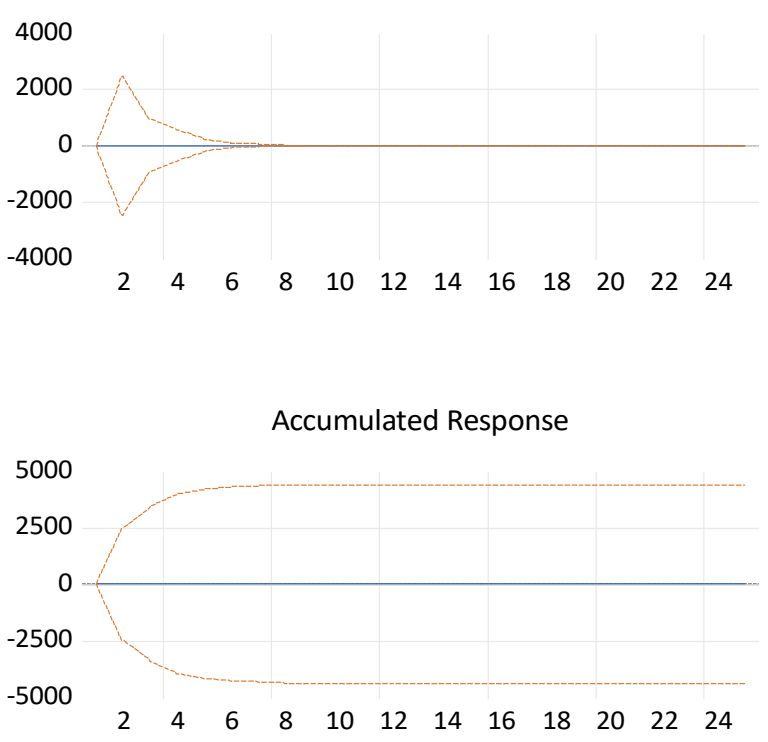

Figure 4. Impulse response of export growth and stock returns to volatility of exchange rate.

\section{Conclusions}

This study developed a triple regime-switching model in which low-, medium-, and high-growth regimes play roles in explaining a substantially detailed relationship between exchange rates, and export turnover and stock returns. The proposed model allows for multistate phenomena to better capture the time-varying aspect of the effect of exchange rates. Applications of the proposed model on the effect of exchange rates suggest that the depreciation of VND most effectively promotes export growth in a moderate-growth state to which the group of agricultural products, raw materials, and unprocessed goods belong. The high-growth state where the depreciation of VND negatively affects exports should belong to the FDI sector where export prices do not depend much on the exchange rate in the short term. Meanwhile, the effect on the stock market is generally negative. Empirical results contradict the usual wisdom of "high risk, high return" in the stock market of Vietnam.

In the context that the USD is depreciating sharply compared to other currencies in the world, the slight appreciation of VND against USD not only does not harm the competitiveness of export businesses, but could also stimulate investment capital flow into Vietnam, reduce the burden of foreign debt payment, lower the trade imbalance between the US and Vietnam, and be the key to escaping from being labeled a currency manipulator by the US Treasury. This policy adjustment of the State Bank is necessary.

Funding: This research received no external funding.

Institutional Review Board Statement: Not applicable.

Informed Consent Statement: Not applicable.

Conflicts of Interest: The author declares no conflict of interest. 


\section{References}

Ajayi, Richard A., Joseph Friedman, and Seyed M. Mehdian. 1998. On the relationship between stock returns and exchange rates: Tests of Granger causality. Global Finance Journal 9: 241-51. [CrossRef]

Andriansyah, Andriansyah, and George Messinis. 2019. Stock prices, exchange rates and portfolio equity flows: A Toda-Yamamoto panel causality test. Journal of Economic Studies 46: 399-421. [CrossRef]

Aristotelous, Kyriacos. 2001. Exchange-rate volatility, exchange-rate regime, and trade volume: Evidence from the UK-US export function (1889-1999). Economics Letters 72: 87-94. [CrossRef]

Arslan, Ismail, and Sweder Van Wijnbergen. 1993. Export incentives, exchange rate policy and export growth in Turkey. The Review of Economics and Statistics, 128-33. [CrossRef]

Bahmani-Oskooee, Mohsen, and Sujata Saha. 2015. On the relation between stock prices and exchange rates: A review article. Journal of Economic Studies 42: 707-32. [CrossRef]

Berman, Nicolas, Philippe Martin, and Thierry Mayer. 2012. How do different exporters react to exchange rate changes? The Quarterly Journal of Economics 127: 437-92. [CrossRef]

Caporale, Guglielmo Maria, John Hunter, and Faek Menla Ali. 2014. On the linkages between stock prices and exchange rates: Evidence from the banking crisis of 2007-10. International Review of Financial Analysis 33: 87-103. [CrossRef]

Chen, Meng-Wei, Cuicui Lu, and Yuan Tian. 2021. Export price and quality adjustment: The role of financial stress and exchange rate. Economic Modelling 96: 336-45. [CrossRef]

Choudhri, Ehsan U., and Dalia S. Hakura. 2015. The exchange rate pass-through to import and export prices: The role of nominal rigidities and currency choice. Journal of International Money and Finance 51: 1-25. [CrossRef]

Dahir, Ahmed Mohamed, Fauziah Mahat, Nazrul Hisyam Ab Razak, and A.N. Bany-Ariffin. 2018. Revisiting the dynamic relationship between exchange rates and stock prices in BRICS countries: A wavelet analysis. Borsa Istanbul Review 18: 101-13. [CrossRef]

Ding, Liang. 2021. Conditional correlation between exchange rates and stock prices. The Quarterly Review of Economics and Finance 80: 452-63. [CrossRef]

Fang, Hsing, and Jean C. H. Loo. 1996. Foreign exchange risk and common stock returns: A note on international evidence. Journal of Business Finance and Accounting 23: 473-80. [CrossRef]

Franck, Peter, and Allan Young. 1972. Stock price reaction of multinational firms to exchange realignments. Financial Management, 66-73. [CrossRef]

Hall, Stephen, George Hondroyiannis, P.A.V.B. Swamy, George Tavlas, and Michael Ulan. 2010. Exchange-rate volatility and export performance: Do emerging market economies resemble industrial countries or other developing countries? Economic Modelling 27: 1514-21. [CrossRef]

Hamilton, James D. 1989. A new approach to the economic analysis of nonstationary time series and the business cycle. Econometrica: Journal of the Econometric Society 57: 357-84. [CrossRef]

Hau, Harald, and Hélène Rey. 2006. Exchange rates, equity prices, and capital flows. The Review of Financial Studies 19: $273-317$. [CrossRef]

Homma, Tetsushi, and Uri Benzion. 2005. Exchange rate and stock prices in Japan. Applied Financial Economics 15: 469-78. [CrossRef]

Kanas, Angelos. 2000. Volatility spillovers between stock returns and exchange rate changes: International evidence. Journal of Business Finance and Accounting 27: 447-67. [CrossRef]

Lee, Jung Wan, and Tantatape Brahmasrene. 2019. Long-run and short-run causality from exchange rates to the Korea composite stock price index. The Journal of Asian Finance, Economics, and Business 6: 257-67. [CrossRef]

Nguyen, Tra Ngoc, Dat Thanh Nguyen, and Vu Ngoc Nguyen. 2020. The impacts of oil price and exchange rate on Vietnamese stock market. The Journal of Asian Finance, Economics and Business 7: 143-50. [CrossRef]

Nguyen, Van Chien, and Thi Tuyet Do. 2020. Impact of exchange rate shocks, inward FDI and import on export performance: A cointegration analysis. The Journal of Asian Finance, Economics, and Business 7: 163-71. [CrossRef]

Pan, Ming-Shiun, Robert Chi-Wing Fok, and Y. Angela Liu. 2007. Dynamic linkages between exchange rates and stock prices: Evidence from East Asian markets. International Review of Economics and Finance 16: 503-20. [CrossRef]

Paudel, Ramesh C., and Paul J. Burke. 2015. Exchange rate policy and export performance in a landlocked developing country: The case of Nepal. Journal of Asian Economics 38: 55-63. [CrossRef]

Phylaktis, Kate, and Fabiola Ravazzolo. 2005. Stock prices and exchange rate dynamics. Journal of International Money and Finance 24: 1031-53. [CrossRef]

Reboredo, Juan Carlos, Miguel A. Rivera-Castro, and Andrea Ugolini. 2016. Downside and upside risk spillovers between exchange rates and stock prices. Journal of Banking and Finance 62: 76-96. [CrossRef]

Sercu, Piet, and Cynthia Van Hulle. 1992. Exchange rate volatility, international trade, and the value of exporting firms. Journal of Banking and Finance 16: 155-82. [CrossRef]

Sui, Lu, and Lijuan Sun. 2016. Spillover effects between exchange rates and stock prices: Evidence from BRICS around the recent global financial crisis. Research in International Business and Finance 36: 459-71. [CrossRef] 